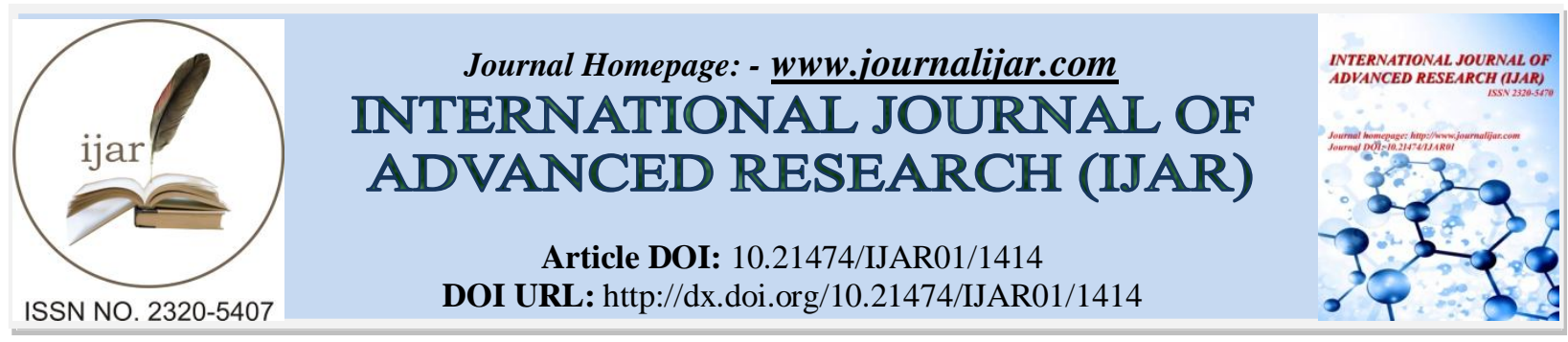

RESEARCH ARTICLE

\title{
NORMALISED DIFFERENCIATIVE VEGETATION INDEX (NDVI) ANALYSIS IN SOUTH-EAST DRY AGRO-CLIMATIC ZONES OF KARNATAKA USING RS AND GIS TECHNIQUES.
}

\author{
Jagadeesha Menappa Kattimani* and T.J.Renuka Prasad.
}

Research Scholar and Professor, Department of Geology, Jnana Bharati Campus, Bangalore University, Bangalore560056 .

\section{Manuscript Info}

Manuscript History

Received: 12 June 2016

Final Accepted: 19 July 2016

Published: August 2016

Key words:-

Vegetation, Soil, Water, NIR, Bands,

Forest and Climate Change.

\section{Abstract}

NDVI shows normal range of -1 to 1 , water, clouds and snow have negative values they reflect more red than IR radiation. Rocks and soils are shows values "Zero" values some reflecting the colour Red and IR radiation only green vegetation has positive and high NDVI values. NDVI change values were extracted for the same pixels that were used for calibration. NDVI Values ranges between -0.33 to 0.03 Water Bodies, 0.03 to 0.19 Non Vegetation, 0.19 to 0.27 Low vegetation, 0.27 to 0.38 Medium Vegetation and 0.38 to 0.77 Dense Vegetation.

Copy Right, IJAR, 2016,. All rights reserved.

\section{Introduction:-}

The NDVI is sensitive to changes in plant canopy and provides unique change information over red and NIR wavebands that compose the NDVI . Basically the NDVI is a numerical indicator range from -1 to +1 that uses the visible and near-infrared bands of the electromagnetic spectrum, and can be calculated as a ratio of red and NIR bands of a sensor system and are represented by the following equation.

Most wildlife and wildlife habitats are extremely threatened due to increasing demands on forestland and forest resources by burgeoning human population. all forms of anthropogenic interactions with the environment are identified as leading causes of climate change, and they in turn impact the environment and climate either positively or negatively. The time series NDVI trend detection, either positive ("greening") or negative ("browning") can be used to identify and quantify recent changes in ecosystem properties from a local to global scale. Therefore, in this study we attempts to understand the changes in vegetation in terms of surface greening and browning to assess the impact of disturbances (Ramesh et.al,).

This is because NDVI carries valuable information regarding land-surface properties, and vegetation changes can be most accurately identified by image differencing of NDVI data. The time-series NDVI data have proven to be appropriate not only for detecting long-term land-use/cover changes but also for modeling terrestrial ecosystems from the global to regional scales.

\section{Location Map:-}

Location of the Study area:-

The study area is forest within the Dry Agro Climatic Region of Karnataka and spreads over in $3294 \mathrm{sqkm}$. It lies between $12^{\circ} 30^{\prime} 0^{\prime \prime}$ and $15^{\circ} 0^{\prime} 0^{\prime \prime}$ latitude and between $75^{\circ} 30^{\prime} 0^{\prime \prime}$ and $78^{\circ} 30^{\prime} 0^{\prime \prime}$ longitude and it encompasses seven 
districts viz., Bangalore Urban, Bangalore Rural, Ramanagara Tumkur, Kolar, Chikkaballapura, Chitradurga. Total district area is 35214 sqkm and the forest area which is focus of the study is only 9\% (Map 1.1).

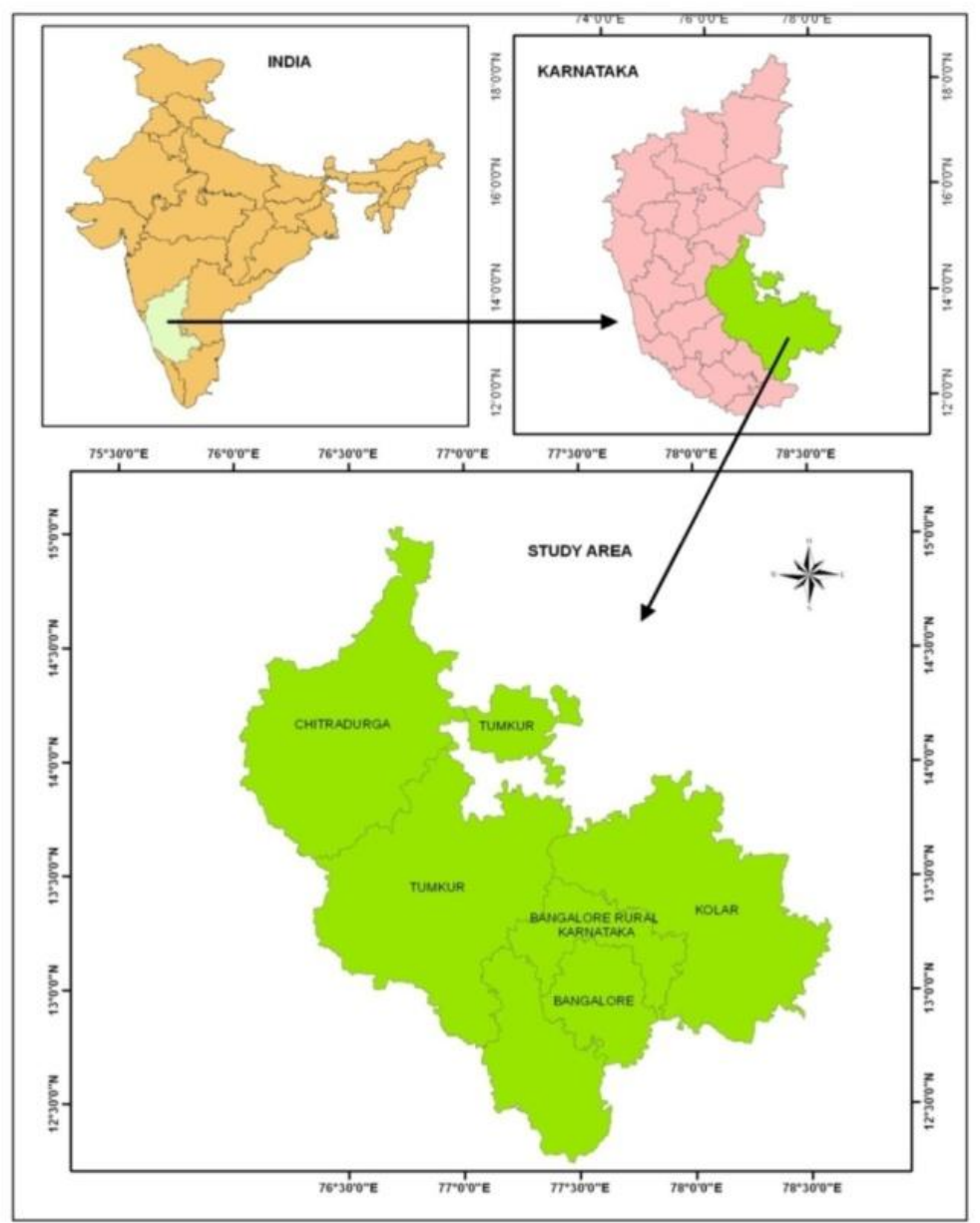

Map 1.1:- Location Map of the study area. 


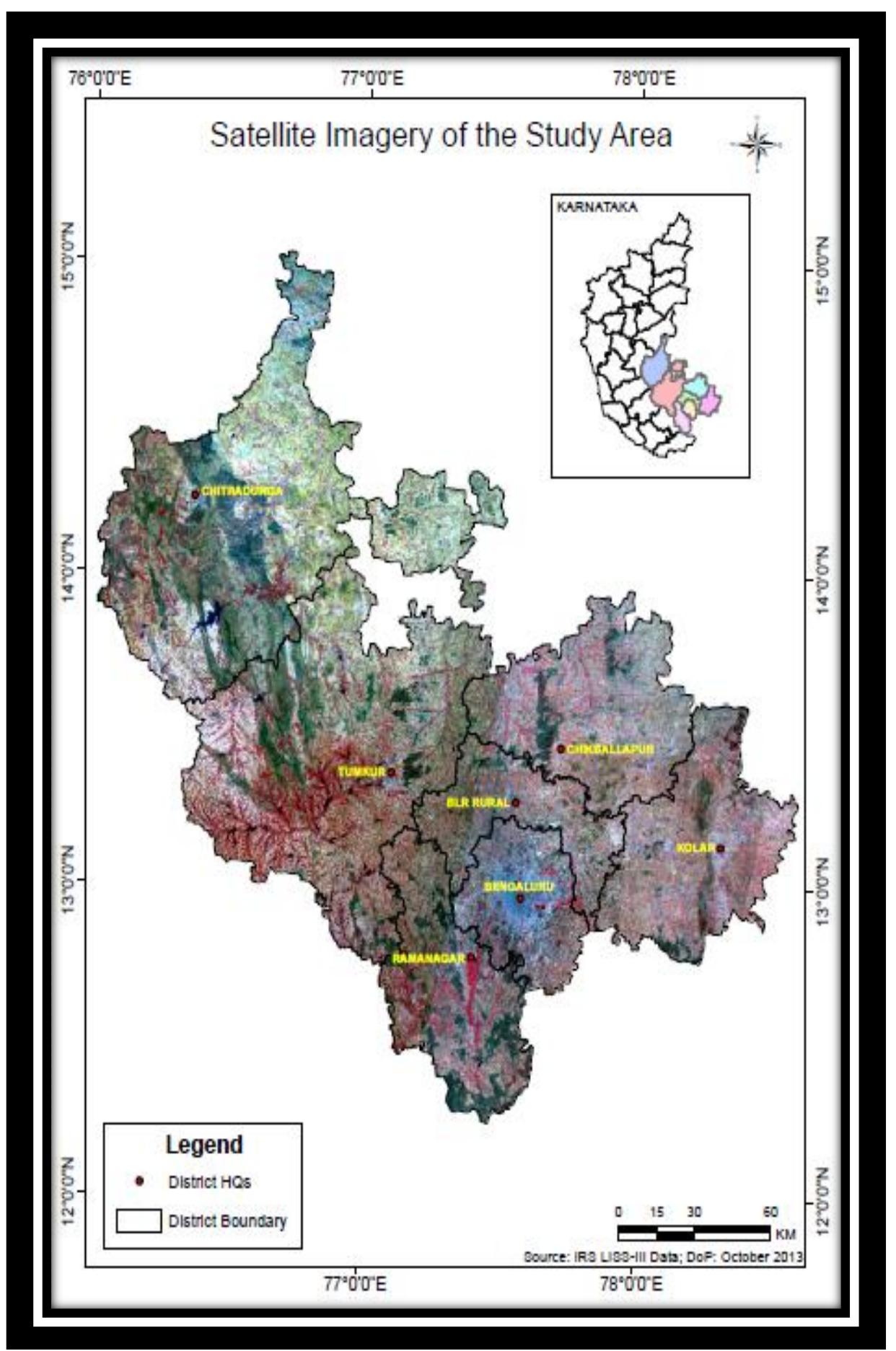




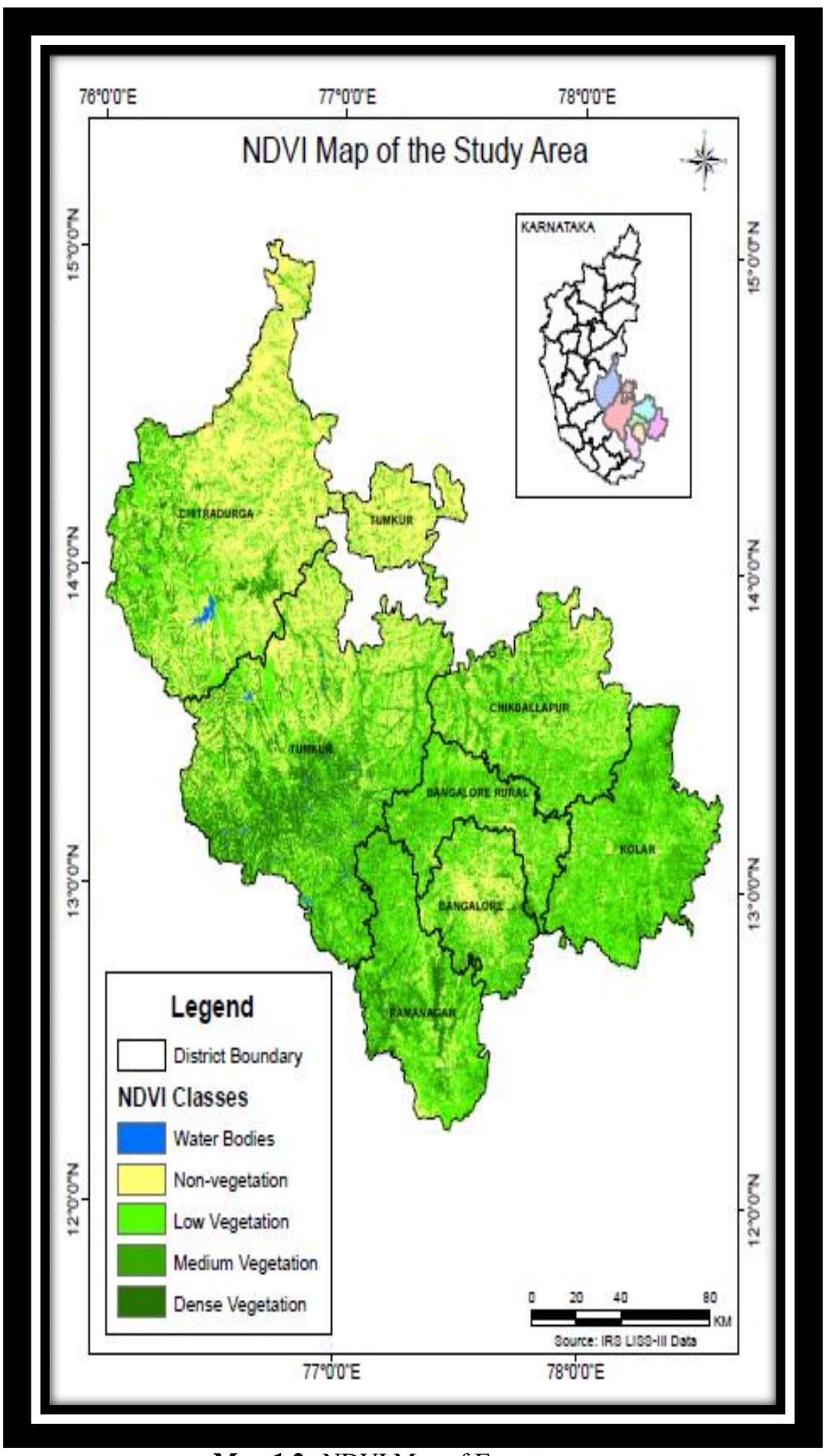

Map 1.2:-NDVI Map of Forest areas. 


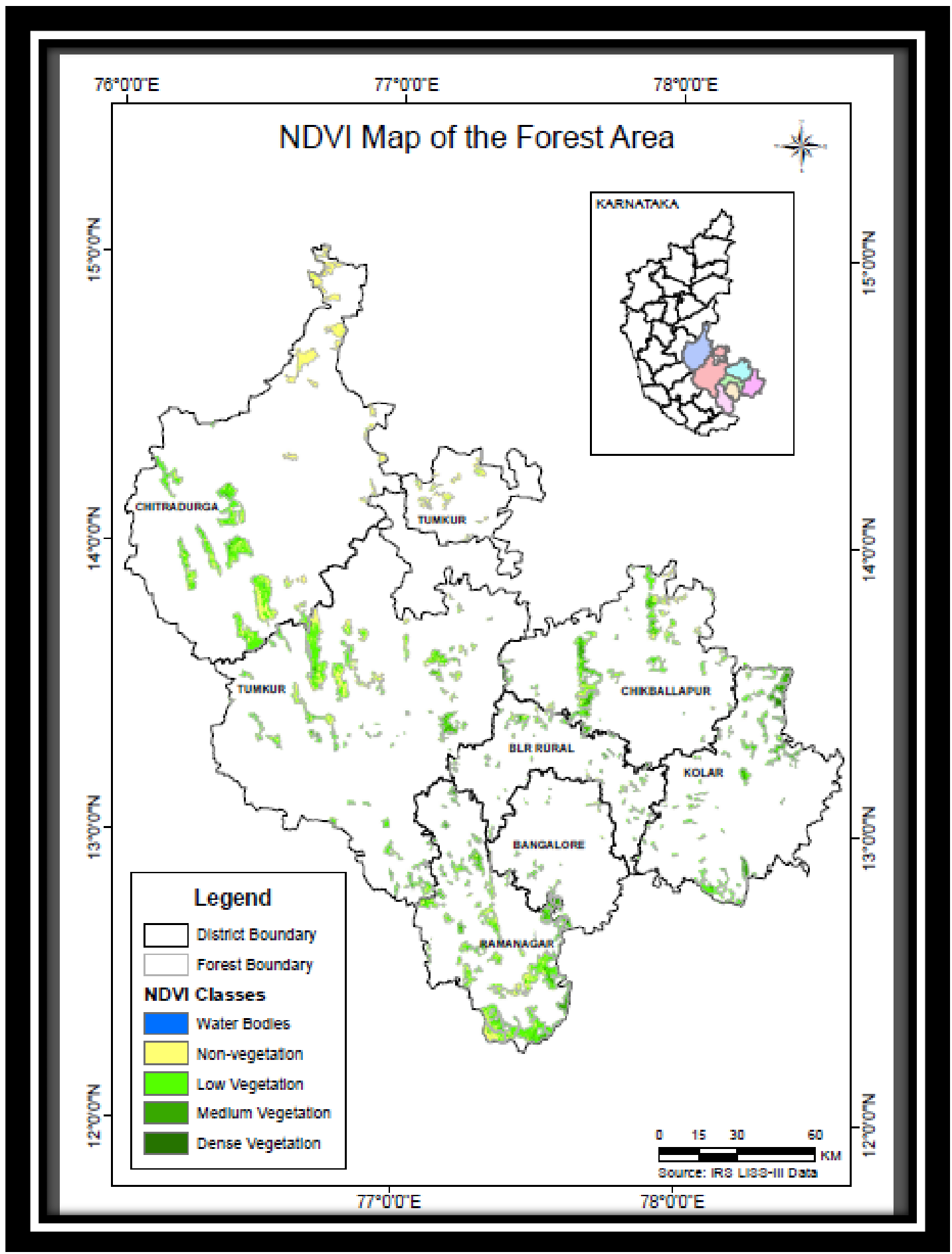

Map 1.3:- NDVI Map of Forest area.

\section{Methodology:-}

In the part of study area grouped into different NDVI ranges -1 to +1 . Creating NDVI Map Steps: LISS III Data $\rightarrow$ Erdas $14 \rightarrow$ Raster $\rightarrow$ NDVI $\rightarrow$ NDVI Vector Map $\rightarrow$ Export to Arc GIS 10.2.1 $\rightarrow$ Spatial Analysis tool $\rightarrow$ Reclassify $\rightarrow$ Raster to Polygon $\rightarrow$ Add Table $\rightarrow$ NDVI values Description $\rightarrow$ Grid code $\rightarrow$ Classifications $\rightarrow$ Legends of NDVI Values $\rightarrow$ Final NDVI MapsThe data was collected in terms of both anthropogenic as well as natural variables that influence the changes. The analyses were carried out by using GIS software 10.2.1 and ERDAS Imagine 14 (Map 1.2). 


\section{Results:-}

In our study, NDVI value ranges from -1 to +1 in this study the quantitative net NDVI change was defined in "percent change" between the years $(1973,2001$ and 2014) For this, NDVI change values were extracted for the same pixels that were used for calibration. NDVI Values ranges between -0.33 to 0.03 Water Bodies, 0.03 to 0.19 Non Vegetation, 0.19 to 0.27 Low vegetation, 0.27 to 0.38 Medium Vegetation and 0.38 to 0.77 Dense Vegetation (Map 1.3).

\section{Acknowledgment:-}

Authors are thankful to the Karnataka State Remote Sensing Application Centre (KSASAC) for producing the satellite data for the study area. Author acknowledges the financial assistance under Rajiv Gandhi National Fellowship (RGNF) 2011-15.

\section{References: -}

1. FSI. (2011). State of Forest Report. Dehra Dun: Forest Survey of India.

2. Hegde, R., Suryaprakash, D., Achoth, D., \& Bawa, D. S. (1996). Extraction of non-timber forest products in the forests of Biligiri Rangan Hills, India. 1. Contribution to rural income. Economic Botany, 50(3), 243-251.

3. Jensen, J. R. (2009). Remote sensing of the environment: An earth resource perspective 2/e. Pearson Education India.

4. Justice, C. O., Townshend, J. R. G., Holben, B. N., \& Tucker, E. C. (1985). Analysis of the phenology of global vegetation using meteorological satellite data. International Journal of Remote Sensing, 6(8), 1271-1318.

5. Mallegowda, P., Rengaian, G., Krishnan, J., \& Niphadkar, M. (2015). Assessing Habitat Quality of ForestCorridors through NDVI Analysis in Dry Tropical Forests of South India: Implications for Conservation. Remote Sensing, 7(2), 1619-1639.

6. Michener, W. K., \& Houhoulis, P. F. (1997). Detection of vegetation changes associated with extensive flooding in a forested ecosystem.Photogrammetric Engineering and Remote Sensing, 63(12), 1363-1374.

7. Murali, K. S., Shankar, U., Shaanker, R. U., Ganeshaiah, K. N., \& Bawa, K. S. (1996). Extraction of non-timber forest products in the forests of Biligiri Rangan Hills, India. 2. Impact of NTFP extraction on regeneration, population structure, and species composition. Economic Botany, 50(3), 252-269.

8. Nduati, E. W., Mundia, C. N., \& Ngigi, M. M. (2013). Effects of vegetation change and land use/land cover change on land surface temperature in the mara ecosystem. Int. J. Sci. Res, 2, 22-28.

9. NDVI in the districts of Balasore and Bhadrak is analogous to 1999 in both the classes. Remaining coastal districts have shown approximately $20 \%$ increase in NDVI greater than 0.5 , which may be attributed to the increase in the forest cover during the period 1995-2010 (Reddy et al. 2012).

10. NRSA. (1985). Forest cover assessment of India using satellite remote sensing data during 1972-1975 and 1980-1982 periods. National Remote Sensing Agency, Hyderabad, India: Technical Report.

11. Puyravaud, J. P., Davidar, P., \& Laurance, W. F. (2010). Cryptic loss of India's native forests. Science, 329(5987), 32-32.

12. Ramesh, R., Purvaja, R., \& Senthil, V. A. (2011). National assessment of shoreline change: Odisha coast. NCSCM/MoEF Report, 57. 